\title{
Nitrogen Uptake from Amino Acids in Maize through Arbuscular Mycorrhizal Symbiosis
}

\author{
Atsushi Matsumura ${ }^{1 *}$, Shinji Taniguchi ${ }^{1}$, Kenji Yamawaki $^{1}$, Rintaro Hattori ${ }^{1}$, Arata Tarui ${ }^{1}$, \\ Katsuya Yano ${ }^{2}$, Hiroyuki Daimon ${ }^{1}$ \\ ${ }^{1}$ Graduate School of Life and Environmental Sciences, Osaka Prefecture University, Osaka, Japan; ${ }^{2}$ Graduate School of Bioagricul- \\ tural Sciences, Nagoya University, Nagoya, Japan. \\ Email: *matsu@plant.osakafu-u.ac.jp
}

Received October $7^{\text {th }}, 2013$; revised November $6^{\text {th }}, 2013$; accepted November $17^{\text {th }}, 2013$

Copyright (C) 2013 Atsushi Matsumura et al. This is an open access article distributed under the Creative Commons Attribution License, which permits unrestricted use, distribution, and reproduction in any medium, provided the original work is properly cited.

\begin{abstract}
Maize plants are well colonized with arbuscular mycorrhizal fungi (AMF), which contribute mineral nutrients absorption from soil. However little is known about their role in nitrogen $(\mathrm{N})$ absorption especially from amino acids, which reach a considerable quantity in soils. This experiment was conducted to investigate $\mathrm{N}$ acquisition from amino acids through AMF symbiosis. AMF inoculation clearly increased the $\mathrm{N}$ content of maize supplied with amino acids (Glu, Ala and Pro). Further study of xylem sap revealed that the composition of amino acids was changed by AMF inoculation. These results indicate that AMF contribute $\mathrm{N}$ from amino acids, and may affect the nitrogen assimilation of host plants.
\end{abstract}

Keywords: Amino Acid Composition; Ala; Glu; Pro; Xylem Sap

\section{Introduction}

A large amount of nitrogen $(\mathrm{N})$ is stored in soil as organic matter, but plants generally prefer to absorb the inorganic forms of $\mathrm{N}\left(\mathrm{NH}^{4+}-\mathrm{N}\right.$ and $\left.\mathrm{NO}^{3-}-\mathrm{N}\right)$, relying on fertilizer application and mineralization by microorganisms. Glu, Gln, Asp and Ala are the most prevalent free amino acids in soil [1]. Chapin et al. [2,3] reported that some plants have developed the ability to directly utilize organic $\mathrm{N}$ compounds from soil, but most plants, especially agricultural plant species, are thought to utilize very small amounts of amino acids and grow better on inorganic $\mathrm{N}$ sources.

Arbuscular mycorrhizal fungi (AMF) are considered to be important to carbon and nutrient fluxes in most agricultural ecosystems [4]. The role of AMF in plant growth and nutrition has been related to the uptake of immobile ions of plant nutrients, such as phosphate. Because of N's high mobility to plant roots through mass flow, it had been suggested that AMF played little role in plant $\mathrm{N} \mathrm{nu}$ trition. However, research on the role of AMF in plant $\mathrm{N}$ nutrition has gradually been accumulating and it has been

"Corresponding author. suggested that AMF can also enhance plant $\mathrm{N}$ acquisition $[5,6]$. Several studies have reported the transport of inorganic $\mathrm{N}$ by AMF to plants $[7,8]$. Recently Govindarajulu et al. [9] revealed that Arg was synthesized from inorganic $\mathrm{N}$ absorbed by extraradical mycelium and translocated to the intraradical mycelium, which exist in host plant roots.

Because of the high $\mathrm{N}$ requirement for maize growth, it is important to investigate whether AMF can acquire organic $\mathrm{N}$ and contribute $\mathrm{N}$ to maize. The objective of this study was to determine the AMF contribution to maize growth and $\mathrm{N}$ acquisition under several amino acid supplemented soil conditions. In our experiment, three amino acids were selected. First is Ala, which is one of the major amino acids present in soil, and can be directly absorbed by plant roots and AMF hyphae because of its reduced molecular weight [10]. Second is Glu, which is also present in considerable quantities in the soil, and is a central junction for interchange of amino acids [11]. Third is Pro, which is one of the most frequently reported as its accumulation is induced by water and salt stress in plants, and its decrease has been reported when plants are colonized by AMF [12]. 


\section{Materials and Methods}

\subsection{Plants and Cultivation}

Three maize seeds (Zea mays L. cv. Gold dent KD850, Kaneko Seeds, Japan) were planted in 1/5000 a Wagner Pot. The growth medium consisted of commercial Akadama soil (Heiwa, Japan) and fertilized granulated soil (Kureha, Japan) at a ratio of 20:1 (v/v). The soil properties were as follows: a $\mathrm{pH}\left(\mathrm{H}_{2} \mathrm{O}\right)$ of 5.9 , an $\mathrm{EC}$ of $0.15 \mathrm{dS}$ $\mathrm{m}^{-1}$, a total $\mathrm{C}$ of $17.2 \mathrm{~g} \mathrm{~kg}^{-1}$, a total $\mathrm{P}$ of $1.42 \mathrm{~g} \mathrm{~kg}^{-1}$, an available phosphorus content (Bray2) of $7.4 \mathrm{mg} \mathrm{kg}^{-1}$, a total $\mathrm{N}$ of $1.37 \mathrm{~g} \mathrm{~kg}^{-1}$, and $66.2 \mathrm{mg} \mathrm{kg}^{-1}$ of inorganic $\mathrm{N}$ $\left(\mathrm{NH}^{4+}-\mathrm{N}+\mathrm{NO}^{3-}-\mathrm{N}\right)$. For AMF inoculation, $20 \mathrm{~g}$ of inoculum (mainly Gigaspora margarita CGC1411 (Central Glass CO. Ltd, Tokyo, Japan), about 300 spores) was placed $2 \mathrm{~cm}$ beneath the sowing layer. Non-inoculated plants received the same volume of sterilized inoculum (autoclaved $20 \mathrm{~min}$ at $121^{\circ} \mathrm{C}$ ). After emergence, the seedlings were thinned to one plant per pot. One of three different amino acid solutions (Ala, Glu or Pro) or water (control) was applied to the maize plants; $100 \mathrm{ml}$ of one amino acid solution ( $400 \mathrm{mg} \mathrm{L}^{-1}$ ) or water was supplied to the pot every 6 days. The total supplied $\mathrm{N}$ as amino acids throughout the experiment was $280 \mathrm{mg}$ per pot. Plants were grown for 41 days from 26 May 2009 to 6 July 2009 in a greenhouse without temperature control. Because visual nutrient deficiency symptoms were observed, $200 \mathrm{ml}$ of Hoagland solution $\left(\mathrm{KNO}_{3} 5 \mathrm{mM}\right.$, $\left.\mathrm{Ca}\left(\mathrm{NO}_{3}\right)_{2} 5 \mathrm{mM}, \mathrm{MgSO}_{4} 7 \mathrm{H}_{2} \mathrm{O} 2 \mathrm{mM}, \mathrm{KH}_{2} \mathrm{PO}_{4} 1 \mathrm{mM}\right)$ was applied to each pot after 22 days of culture (17 June 2009). Seven replications were performed of each treatment, and pots were arranged in a randomized complete block design. Five plants in each treatment were sampled to investigate plant biomass, $\mathrm{N}$ and $\mathrm{P}$ content and AMF root colonization. A root tissue subsample was used for the determination of AM root colonization. For root colonization, roots were stained by the technique of Phillips and Hayman [13] and percentage of AMF root colonization was determined using the grid-line intersection method [14].

\subsection{N, $P$ and Amino Acid Analysis}

At the sampling time, shoots and roots were harvested and their biomass was determined after drying at $70^{\circ} \mathrm{C}$ for $48 \mathrm{~h}$. Then ground shoot and root tissue digestion were completed and tissue $\mathrm{N}$ and $\mathrm{P}$ concentration were measured by vario MAX CN (Elementar, Germany) and ICP (Vista-MPX), respectively. For xylem sap collection, the two remaining shoots from each treatment were cut $30 \mathrm{~mm}$ above the ground, and root sap was collected in a capillary tube. Xylem sap samples were stored at $-20^{\circ} \mathrm{C}$ until analysis. Individual amino acids in the xylem sap were quantified by CE/MS (G1310A/G1600A/G6130A;
Agilent Technologies) with a FunCap-CE/Type S capillary (GL Sciences).

\subsection{Data Analysis}

Data were analyzed using IBM SPSS Statistics 19. Oneway ANOVA followed by Tukey's test was performed to determine the mycorrhizal colonization differences between amino acid treatments. Two-way ANOVA with Bonferroni post-test was used to determine the difference between the AMF treatment, the amino acid treatments, and the possible interactions of each. Differences were considered significant at $p<0.05$. Principal component analysis (PCA) was used to characterize amino acid composition of xylem sap. Data obtained by CE/MS were interpreted by PCA using the first two PCs (PC1 and $\mathrm{PC} 2$ ), which were subsequently plotted to visualize the results.

\section{Results and Discussion}

All plants inoculated with AMF were colonized at levels ranging from $37 \%$ to $63 \%$. Inoculation with $\mathrm{AMF}$ significantly increased maize dry matter production (Table 1). Without AMF, the Glu supplement increased shoot dry weight, while Pro had a detrimental effect on both shoot dry weight and root dry weight although significant differences were not observed. When plants were inoculated with AMF, shoot dry matter production was significantly increased by amino acid supplement.

The $\mathrm{N}$ content of shoots and roots was not significantly increased by amino acid supplements in the noninoculated treatment. When plants were inoculated with AMF, the $\mathrm{N}$ content clearly increased under all amino acid treatments when compared to the control. The $\mathrm{P}$ content of Ala and Pro treated plants decreased when compared to control plants without AMF. However, P was significantly increased by AMF inoculation, especially when inoculated with AMF and supplemented with Pro.

Our results indicated that different amino acid sources had different effects on growth and $\mathrm{N}$ and $\mathrm{P}$ content of maize plants. It has been suggested that amino acids affect plant growth differently [15]. For example, Trp and Met applied to soil had a positive impact on plant growth [16-18]. The application of Glu increased maize growth and $\mathrm{N}$ content both with and without AMF in our experiment. Since Glu acts as a precuesor for further metabolites, Glu, which was absorbed directly, could be converted to other amino acids or proteins efficiently. On the other hand, Ala had no effect on plant growth and Pro inhibited growth. This might be related to the different chemical properties and functions of individual amino acids in the nitrogen cycle.

The composition of amino acids in xylem sap was in- 
Table 1. Dry weight, $\mathbf{N}$ content and $P$ content of maize supplemented with different amino acids and with or without AMF inoculation.

\begin{tabular}{|c|c|c|c|c|c|c|c|c|}
\hline \multirow[b]{2}{*}{ Treatment } & \multirow[b]{2}{*}{$\mathrm{AMF}$} & \multicolumn{2}{|c|}{ Dry weight (g plant ${ }^{-1}$ ) } & \multicolumn{2}{|c|}{$\mathrm{N}$ content $\left(\mathrm{mg}\right.$ plant $\left.^{-1}\right)$} & \multicolumn{2}{|c|}{$\mathrm{P}$ content (mg plant $\left.{ }^{-1}\right)$} & \multirow{2}{*}{$\begin{array}{l}\text { AMF colonization } \\
(\%)\end{array}$} \\
\hline & & Shoot & Root & Shoot & Root & Shoot & Root & \\
\hline \multirow[t]{2}{*}{ Control } & - & $2.4 \mathrm{c}$ & $2.4 \mathrm{~cd}$ & $50.8 \mathrm{~cd}$ & $38.2 \mathrm{~cd}$ & $12.4 \mathrm{c}$ & $11.6 \mathrm{c}$ & - \\
\hline & + & $4.6 \mathrm{~b}$ & $3.4 \mathrm{ab}$ & $85.5 \mathrm{~b}$ & $49.2 \mathrm{c}$ & $24.0 \mathrm{~b}$ & $20.7 \mathrm{~b}$ & $62.7 \mathrm{a}$ \\
\hline \multirow[t]{2}{*}{ Glu } & - & $3.1 \mathrm{c}$ & $2.6 \mathrm{c}$ & $72.1 \mathrm{c}$ & $45.3 \mathrm{c}$ & $14.3 \mathrm{c}$ & $9.9 \mathrm{c}$ & - \\
\hline & + & $6.2 \mathrm{a}$ & $3.5 \mathrm{ab}$ & $166.0 \mathrm{a}$ & $71.3 \mathrm{~b}$ & $49.0 \mathrm{a}$ & $23.0 \mathrm{~b}$ & $36.5 \mathrm{a}$ \\
\hline \multirow[t]{2}{*}{ Ala } & - & $2.4 \mathrm{c}$ & $2.1 \mathrm{~cd}$ & $56.1 \mathrm{~cd}$ & $35.3 \mathrm{~cd}$ & $8.8 \mathrm{~cd}$ & $7.5 \mathrm{~cd}$ & - \\
\hline & + & $5.4 \mathrm{ab}$ & $3.2 \mathrm{~b}$ & $162.7 \mathrm{a}$ & $71.1 \mathrm{~b}$ & $45.5 \mathrm{a}$ & $22.8 \mathrm{~b}$ & $47.2 \mathrm{a}$ \\
\hline \multirow[t]{2}{*}{ Pro } & - & $1.9 \mathrm{c}$ & $1.7 \mathrm{~d}$ & $45.7 \mathrm{~d}$ & $27.1 \mathrm{~d}$ & $5.3 \mathrm{~d}$ & $3.2 \mathrm{~d}$ & - \\
\hline & + & $6.2 \mathrm{a}$ & $4.0 \mathrm{a}$ & $166.1 \mathrm{a}$ & $87.2 \mathrm{a}$ & $44.0 \mathrm{a}$ & $32.2 \mathrm{a}$ & $39.8 \mathrm{a}$ \\
\hline \multicolumn{9}{|l|}{ Significance } \\
\hline \multicolumn{2}{|c|}{ Amino acid (A) } & $*$ & ns & * & * & * & ns & ns \\
\hline \multicolumn{2}{|c|}{ AMF (B) } & * & ${ }^{*}$ & * & ${ }^{*}$ & * & * & - \\
\hline \multicolumn{2}{|c|}{$\mathrm{A} \times \mathrm{B}$} & * & ${ }^{*}$ & ${ }^{*}$ & ${ }^{*}$ & ${ }^{*}$ & ${ }^{*}$ & - \\
\hline
\end{tabular}

Means with the same letter in each column have no significant difference $(p<0.05)$. ns represents non-significance and $*$ represents significance at $p<0.05$.

vestigated in order to clarify the effect of amino acid treatment and AMF inoculation. The majority of the amino acids in xylem sap were Gln and Asn, at 48\% $57 \%$ and $9 \%-23 \%$, respectively (data not shown). Before conducting the experiment we expected to see small amounts of the supplied amino acids (Ala, Glu and Pro) absorbed directly by maize roots resulting in a higher concentration of them in xylem sap, but the level of individual amino acids in xylem sap did not increase. The composition of amino acids in xylem sap was clearly different between AMF inoculated and non-inoculated plants. The concentration of most amino acids (Ala, Leu, Ile, Val, Ser, Thr, Gly, Met, His, Lys, Asp and Gln) increased, and those of Pro, Phe and Asn decreased in AMF inoculated compared to non-inoculated plants. Since Pro is produced by the plant in relatively huge quantities during times of stress to assist with osmotic balance, the decrease of Pro concentration in AMF treatment could be due to the stress alleviation by AMF through improvement of nutrient and water status. The PCA plot explained $72 \%$ of total variance with PC1 accounting for 52\% (Figure 1(a)). Plants were divided into two groups: AMF inoculated plants and non-inoculated plants. Amino acid loadings, which contribute to the plot pattern, are shown in Figure 1(b). Most amino acids were plotted to the right of the origin and Glu took a middle position. However, Asn, Pro, Phe, Met and Arg were plotted to the left of the origin. According to Figure 1, maize inoculated with AMF had greater concentrations of most amino acids and lower concentrations of Asn, Pro, Phe, Met and Arg compared to maize without AMF. The PCA result showed that the amino acids' concentration in xylem sap did not differ among amino acid treatments. According to these results, amino acids, which were in soil, could be absorbed by AMF mycelium and transformed into Arg in AMF hyphae as suggested by Govindarajulu et al. [9].

We verified that AMF can stimulate plant growth in the presence of amino acids. For example the inhibitory effect of Pro observed without AMF treatment was greatly improved by AMF inoculation. George et al. [19] suggested that $\mathrm{N}$ uptake by AMF itself is usually low compared to the total demand by plants but in our experiment $\mathrm{AMF}$ increased the growth and $\mathrm{N}$ content of maize supplied with amino acid dramatically. We have not determined the mechanism by which AMF could increase $\mathrm{N}$ absorption of maize. The advantage of acquiring $\mathrm{N}$ from amino acids and a mycorrhizal symbiont may be related to increased production of extracellular degradative enzymes rather than to direct facilitation of amino acid transport or to the enlargement of the root system, since there was a slight positive effect from Glu application but not in Ala and Pro treatments unless they also had an AMF treatment. The mycelium of AMF has the ability to excrete hydrolytic enzymes [20]. Various hydrolytic enzymes such as cellulase, pectinase, and xyloglucanase have been reported in external mycelium of AMF [21,22]. These enzymes are known to be involved in the degradation of organic matters in soil. Cappellazzo et al. [23] reported that among AMF, Glomus mosseae 


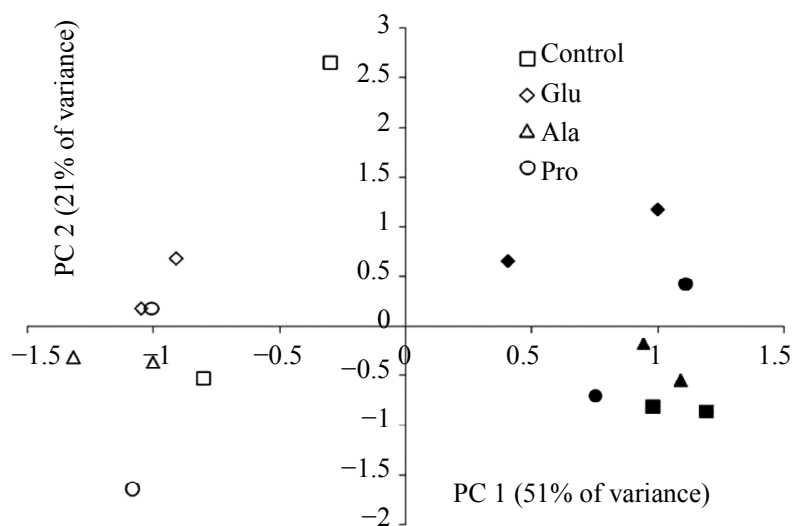

(a)

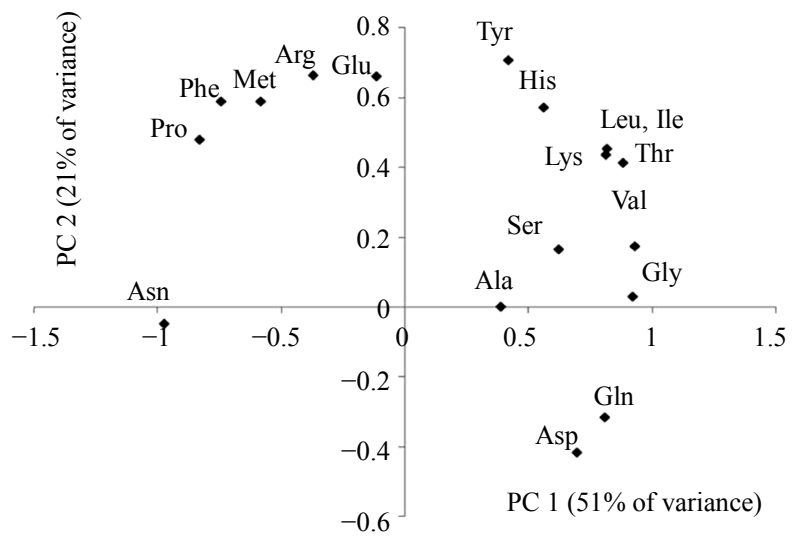

(b)

Figure 1. Principal component analysis (PCA) of amino acids in xylem sap of maize (a). Loading of amino acids in PCA (b). Open symbols and solid symbols in A indicate nonAMF inoculated maize and AMF inoculated maize, respectively.

possesses molecular tools for direct amino acid uptake. Although it is unknown whether G. margarita, which was used in our experiment, possesses amino acid permeases, this fungus also has enzymes such as AmosAAP1 in external mycelium.

Little is known about the effect of AMF on the composition of amino acids in xylem sap. The chemistry of xylem fluid is not stable and changes with temperature, light conditions, water stress, and soil nutrient status. Different compositions of amino acids in xylem sap induced by AMF colonization might be the consequence of different $\mathrm{P}$ statuses in maize. Further experiments are needed to reveal the mechanisms of this phenomenon. Consequently, since amino acids are found in a wide range of soils, AMF symbiosis would play a considerable role in the $\mathrm{N}$ acquisition of plants in agro-ecosystems.

\section{Acknowledgements}

We would like to thank NPO Nanko Ume Group members for helpful discussions. This work was supported in part by a Research Grant for Promoting and Developing Sound Material-cycle Societies (No. K2182) from the Ministry of Environment, Japan.

\section{REFERENCES}

[1] S. M. Abuarghub and D. J. Read, "The Biology of Mycorrhiza in the Ericaceae. XII. Quantitative Analysis of individual Free Amino Acids in Relation to Time and Depth in the Soil Profile," New Phytologist, Vol. 108, No. 4, 1988, pp. 433-441. http://dx.doi.org/10.1111/j.1469-8137.1988.tb04184.x

[2] F. S. Chapin III., L. Moilanen and K. Kiell, "Preferential Use of Organic Nitrogen for Growth by a Non-Mycorrhizal Artic Sedge," Nature, Vol. 361, No. 6408, 1993, pp. 150-153. http://dx.doi.org/10.1038/361150a0

[3] F. S. Chapin III., "New Cog in the Nitrogen Cycle," Nature, Vol. 377, No. 6546, 1995, pp. 199-200. http://dx.doi.org/10.1038/377199a0

[4] S. E. Smith and D. J. Read, "Mycorrhizal Symbiosis," Academic Press, San Diego, 1997.

[5] R. N. Ames, L. K., St. Porter, T. V. John and C. P. P. Reid, "Nitrogen Sources and 'A' Values for VesicularArbuscular and Non-Mycorrhizal Sorghum Grown at Three Rates of ${ }^{15} \mathrm{~N}$-Ammonium Sulphate," New Phytologist, Vol. 97, No. 2, 1984, pp. 269-276. http://dx.doi.org/10.1111/j.1469-8137.1984.tb04131.x

[6] C. Azcón-Aquilar, C. Alba, M. Montilla and J. M. Barea, "Isotopic $\left({ }^{15} \mathrm{~N}\right)$ Evidence of the Use of Less Available N Forms by VA Mycorrhizas," Symbiosis, Vol. 15, No. 1-2, 1993, pp. 39-48.

[7] R. N. Ames, C. P. P. Reid, L. K. Porter and C. Cambardella, "Hyphal Uptake and Transport of Nitrogen from two ${ }^{15} \mathrm{~N}$-Labelled Sources by Glomus mosseae, a Vesicular-Arbuscular Mycorrhizal Fungus," New Phytologist, Vol. 95, No. 3, 1983, pp. 381-396. http://dx.doi.org/10.1111/j.1469-8137.1983.tb03506.x

[8] J. P. Toussaint, M. St-Arnaud and C. Charest, "Nitrogen Transfer and Assimilation between the Arbuscular Mycorrhizal Fungus Glomus intraradices Schenck \& Smith and Ri T-DNA roots of Daucus carota L. in an in Vitro Compartmented System," Canadian Journal of Microbiology, Vol. 50, No. 4, 2004, pp. 251-260.

http://dx.doi.org/10.1139/w04-009

[9] M. Govindarajulu, P. E. Pfeffer, H. Jin, J. Abubaker, D. D. Doud, J. W. Allen, H. Bücking, P. J. Lammers and Y. Shachar-Hill, "Nitrogen Transfer in the Arbuscular Mycorrhizal Symbiosis," Nature, Vol. 435, No. 7043, 2005, pp. 819-823. http://dx.doi.org/10.1038/nature03610

[10] H. Manabe and K. Ohira, "Effects of D- and L-Alanine on the Growth of Suspension-Cultured Rice, Soybean and Tobacco Cells," Soil Science and Plant Nutrition, Vol. 27, No. 3, 1981, pp. 383-386. http://dx.doi.org/10.1080/00380768.1981.10431293

[11] S. Hou, H. He, H. Zhang, H. Xie and X. Zhang, "Determination of Soil Amino Acids by High Performance Liquid Chromatography-Electro Spray Ionization-Mass Spectrometry Derivatized with 6-Aminoquinolyl-N-Hydroxy- 
succinimidyl Carbamate," Talanta, Vol. 80, No. 2, 2009, pp. 440-447.

http://dx.doi.org/10.1016/i.talanta.2009.07.013

[12] P. Sivakumar, P. Sharmila and P. P. Saradhi, "Proline Alleviates Salt-Stress-Induced Enhancement in Ribulose1,5-Bisphosphate Oxygenase Activity," Biochemical Biophysical Research Communications, Vol. 279, No. 2, 2000, pp. 512-515. http://dx.doi.org/10.1006/bbrc.2000.4005

[13] J. M. Phillips and D. S. Hayman, "Improved Procedures for Clearing Roots and Staining Parasitic and Vesicular-Arbuscular Mycorrhizal Fungi for Rapid Assessment of Infection," Transactions of the British Mycological Society, Vol. 55, No. 1, 1970, pp. 158-161. http://dx.doi.org/10.1016/S0007-1536(70)80110-3

[14] M. Giovannetti and B. Mosse, "An Evaluation of Techniques for Measuring Vesicular Arbuscular Mycorrhizal Infection in Roots," New Phytologist, Vol. 84, No. 3, 1980, pp. 489-500. http://dx.doi.org/10.1111/j.1469-8137.1980.tb04556.x

[15] W. Liu, S. J. Li and D. K. Chen, "Use of Amino Acid Nitrogen for Growth by Pak-Choi under Sterile Culture," Acta Horticulturae, Vol. 627, 2003, pp. 131-138.

[16] W. T. Jr. Frankenberger, A. C. Chang and M. Arshad, "Response of Raphanus sativus to the Auxin Precusor, L-Tryptophan Applied to Soil," Plant and Soil, Vol. 129, No. 2, 1990, pp. 235-241.

[17] M. Arshad and W. T. Frankenberger Jr., "Response of Zea mays L. and Lycopersicon esculentum to the Ethylene Precursors, L-Methionine and L-Ethionine Applied to Soil," Plant and Soil, Vol. 122, No. 2, 1990, pp. 219-227. http://dx.doi.org/10.1007/BF02851979

[18] M. Arshad, A. Hussain and A. Shakoor, "Effect of Soil
Applied L-Tryptophan on Growth and Chemical Composition of Cotton," Journal of Plant Nutrition, Vol. 18, No. 2, 1995, pp. 317-329. http://dx.doi.org/10.1080/01904169509364904

[19] E. George, H. Marschner and I. Jakobsen, "Role of Arbuscular Mycorrhizal Fungi in Uptake of Phosphorus and Nitrogen from Soil," Critical Reviews in Biotechnology, Vol. 15, No. 3-4, 1995, pp. 257-270. http://dx.doi.org/10.3109/07388559509147412

[20] A. Varma, "Hydrolytic Enzymes from Arbuscular Mycorrhizae: The Current Status," In: A. Varma and B. Hock, Eds., Mycorrhiza, 2nd Edition, Springer, Berlin, 1999, pp. 373-389.

http://dx.doi.org/10.1007/978-3-662-03779-9 15

[21] I. Garcia-Romera, J. M. Garcia-Garrido and J. A. Ocampo, "Pectolytic Enzymes in the Vesicular-Arbuscular Mycorrhizal Fungus Glomus mosseae," FEMS Microbiology Letters, Vol. 78, No. 2-3, 1991, pp. 343-346. http://dx.doi.org/10.1111/j.1574-6968.1991.tb04467.x

[22] J. M. Garcia-Garrido, I. Garcia-Romera and J. A. Ocampo, "Cellulase Production by the Vesicular-Arbuscular Mycorrhizal Fungus Glomus mosseae (Nicol. \& Gerd.) Gerd. and Trappe," New Phytologist, Vol. 121, No. 2, 1992, pp. 221-226.

http://dx.doi.org/10.1111/j.1469-8137.1992.tb01107.x

[23] G. Cappellazzo, L. Lanfranco, M. Fitz, D. Wipf and P. Bonfante, "Characterization of an Amino Acid Permease From the Endomycorrhizal Fungus Glomus mosseae," Plant Physiology, Vol. 147, No. 1, 2008, pp. 429-437. http://dx.doi.org/10.1104/pp.108.117820 